\title{
Modelling and Forecasting the Balance of Trade in Ethiopia
}

\author{
Yibeltal Arega Ashebir*, Tewodros Getinet Yirtaw, Anteneh Asmare Godana \\ Department of Statistics, University of Gondar, Gondar, Ethiopia \\ Email address: \\ mamush77@yahoo.com (Y. A. Ashebir), tedomanchu@yahoo.com (T. G. Yirtaw), antasmare@gmail.com (A. A. Godana) \\ To cite this article: \\ Yibeltal Arega Ashebir, Tewodros Getinet Yirtaw, Anteneh Asmare Godana. Modelling and Forecasting the Balance of Trade in Ethiopia. \\ American Journal of Theoretical and Applied Statistics. Special Issue: Computational Statistics. Vol. 4, No. 1-1, 2015, pp. 19-23. \\ doi: 10.11648/j.ajtas.s.2015040101.14
}

\begin{abstract}
For a long period of time, Ethiopia has involved in foreign trade and experienced trade deficit several time in the past. This deficit can be largely explained by the unequal terms of trade between agricultural commodities (the country's major export) and capital goods (the country's major import). The core objective of study was to model the balance of trade in Ethiopia and forecast its value through ARIMA model by using annual data from 1974/75 to 2009/10. The appropriate model was ARIMA $(3,1,0)$ and the forecasted value of balance of trade is expected to raising time to time from 2010/11 up to 2015/16.
\end{abstract}

Keywords: Trade Balance, ARIMA

\section{Introduction}

When we compare one country to another we can see differences in economic structure and economic dependence. This economic dependence creates economic interrelationships among the countries in the real world. As a consequence, foreign trade comes into existence. In general this trade covers many countries in the world. Due to this we can say foreign trade is an international trade. International trade consists of the export trade and import trade. According to demand and supply of international market structure, countries of the world create economic interrelationship. Actually the main benefit from increasing export is usually to increasing the capacity to import intermediate inputs and other goods and services which are necessary or helpful to faster economic development in the domestic market.

Ethiopia has tried to implement completely different trade strategies in the past, including a strategy of import replacement/protection for infant industries during the imperial period, a heavily state-managed trading system during the military government era, and a market-oriented liberalized approach supported by the international financial institutions in the most recent period. Each of these trade regimes incorporated the policy objective of diversifying Ethiopia's export palette to reduce dependence on coffee and other cash crops. Numerous trade related technical assistance projects have already been implemented. Policies promoting exports have been adopted.

Ethiopia has experienced trade deficit several time in the past. Ethiopia's trade deficit can be largely explained by the unequal terms of trade between agricultural commodities (the country's major exports) and capital goods (the country's major imports). It is projected to reach an all time high of USD 6.7 billion (NBE, 2007).

The deficit of Ethiopia's trade balance can be interpreted in to two ways. On the positive note, the fact that the value of imports is taken up by capital goods plus intermediate inputs is in fact an indication of growth domestic economy and expanding productive capacity of the country at an increasing rate. On a negative note, it can be seen as cause for alarm since such a wide and growing gap between the value of exports and imports of a country means that the country continues to need other sources of financing such as foreign aid and credit.

\section{Methodology}

\subsection{Variable and Sources of Data}

This study uses secondary data on balance of trade (in million birr) in Ethiopia for the period 1974/75 to 2009/10 from National Bank of Ethiopia (NBE).

Balance of trade (BT): - The difference in value between a country's total exports and imports over a specific period of time.

\subsection{Stationarity}

A given series is said to be stationary if its mean and variance are constant over time and the value of the covariance 
between any two time periods depends only on the distance or gap or lag between the two time periods and not the actual time at which the covariance is computed.

\subsection{AR and $M A$}

The auto correlation function of pure AR (p) processes should decay gradually at increasing lag length. If the ACF exhibits slow decay and the PACF cuts off sharply after lag $p$, we would identify the series as AR (p). And the behavior of the Correlogram and partial Correlogram of the pure MA (q) is the inverse of pure AR (p) processes. The auto Correlogram of pure MA (q) process should die out after q lags. The partial auto Correlogram of pure MA process, on other hand, only decays slowly over time (similar to auto Correlogram of pure AR process).

\subsection{ARMA Process}

Autoregressive moving average (ARMA) modeling is a specific subset of univariate modeling in which a time series is expressed in terms of past values of itself (the autoregressive component) plus current and lagged values of a 'white noise' error term (the moving average component). In general, an
ARMA model is characterized by the notation ARMA $(p, q)$ where, $p$ and $q$ are orders of autoregressive and moving average respectively.

\subsection{ARIMA Process}

Autoregressive Integrated Moving Average (ARIMA) model was introduced by Box and Jenkins (hence also known as Box-Jenkins model) in 1960s for forecasting a variable. Autoregressive Integrated Moving-Average (ARIMA) models consist of unit-root non-stationary time series which can be made stationary by the order of integration ' $d$ '.

\section{Results and Discussions}

\subsection{Descriptive Statistics}

The summary statistics for the balance of trade is as given in the following table. The average value of balance of trade was -6.98 million birr and the maximum and minimum balance of trade was -0.25 and -28.86 million birr respectively over the period $1974 / 75$ to $2009 / 10$.

Table 1. Summary statistics for balance of trade

\begin{tabular}{lllll}
\hline & Mean & Maximum & Minimum & Standard deviation \\
\hline Balance of trade & -6.98 & -0.25 & -28.86 & 3.84 \\
\hline
\end{tabular}

The value of balance of trade has increased negatively in most of the years. From the $1974 / 75$ up to $1990 / 91$, balance of trade exhibits relatively small drop annually but after 1990/91 onwards it shows a sharp drop as shown in the following figure.

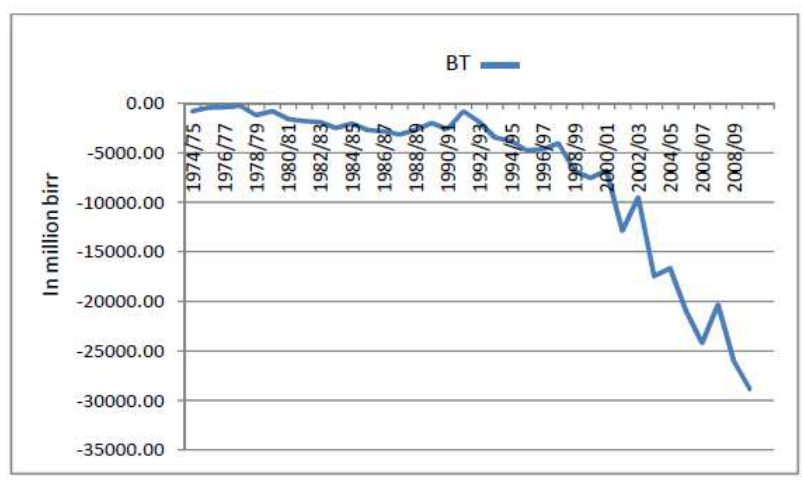

Fig1.Balance of trade in Ethiopia from 1974/75 to 2009/10

\subsection{ARIMA Model for Balance of Trade in Ethiopia}

Table 2. ADF test for BT at level

\begin{tabular}{llll}
\hline \multirow{2}{*}{ Augmented Dickey-Fuller test Statistic } & t-Statistics & Prob.* \\
\cline { 3 - 4 } & & $\mathbf{1 . 3 6 5 7 0 3}$ & $\mathbf{0 . 9 9 9 9}$ \\
\hline Test Critical Value: & $1 \%$ level & -4.262735 & \\
& $1 \%$ level & -3.552973 & \\
$10 \%$ level & -3.209642 & \\
\hline
\end{tabular}

MacKinnon (1996) one-sided p-value

The ARIMA modeling consist identification, estimation and diagnostic checking. To assess non stationarity, result of $\mathrm{ADF}$ for $\mathrm{BT}$ is given in the following table.

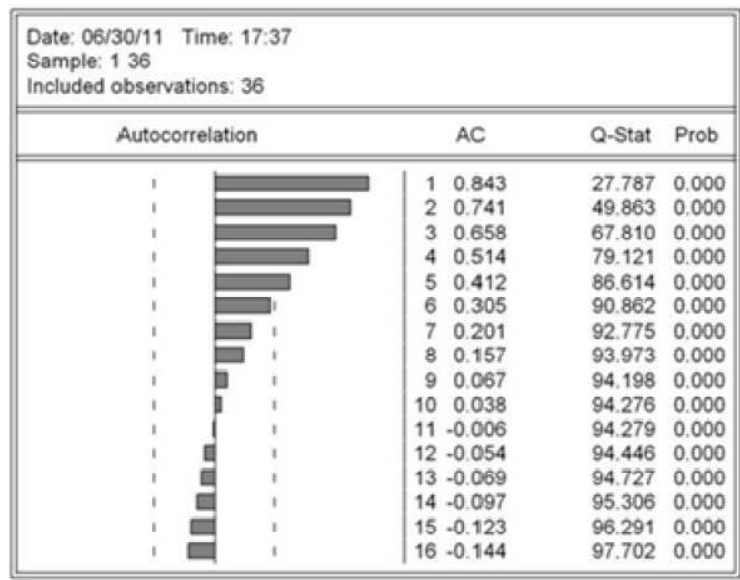

Fig 2. Correlogram for BT at level

The test statistic (1.365703) was greater than the critical value $(-3.552973)$ with $p$ value (0.9999). This implies that we fail to reject the null hypothesis that is there is a unit root problem at $5 \%$ level of significance. In addition to ADF test, the correlogram autocorrelation (Figure 2) shows that the autocorrelation function does not tail of quickly. This proves the presence of unit root in the series of balance of trade.

Due to the presence of unit root problem, we have to consider the first difference of the balance of trade data to make it stationary. 
Table 3. ADF test for BT at first difference

\begin{tabular}{lll}
\hline & t-Statistic & Prob. $^{*}$ \\
\hline Augmented Dickey-Fuller test Statistic & -5.782298 & 0.0002 \\
\hline
\end{tabular}

From table 3 we can conclude that the BT time series data becomes stationary after the first difference.

\subsection{Model Identification and Estimation}

Because of highly subjective nature of the Box-Jenkins methodology, time series analysts have sought alternative objective methods for identifying ARIMA models. The penalty function statistics such Akakie's Information Criterion (AIC) and Schwarz's Bayesian criterion (SBC) are often used in the identification of ARIMA models. Usually the smallest $\mathrm{AIC}$ or $\mathrm{BIC}$ value is preferred.

\begin{tabular}{|c|c|c|c|c|c|c|}
\hline \multicolumn{7}{|c|}{$\begin{array}{l}\text { Date: 05/09/06 Time: 03:06 } \\
\text { Sample: } 136 \\
\text { Included observations: } 35\end{array}$} \\
\hline Autocorrelation & Partial Cor & rrelation & $A C$ & PAC & Q-Stat & Prob \\
\hline$\square$ & $\square$ & 1 & $1-0.457$ & -0.457 & 7.9704 & 0.005 \\
\hline 10 & 18 & 1 & 20.314 & 0.133 & 11.850 & 0.003 \\
\hline ，巨， & $\therefore E$ & $\square$ & 30.180 & 0.471 & 13. 168 & 0.004 \\
\hline & & 1 & $4-0.192$ & 0.009 & 14.715 & 0.005 \\
\hline$\exists$ & $\because \mathrm{E}$ & 当 & $\begin{array}{ll}5 & 0.437\end{array}$ & 0.240 & 22.947 & 0.000 \\
\hline 10 & 18 & 1 & $6-0.182$ & 0.107 & 24.419 & 0.000 \\
\hline 171 & 11 & i & 70.136 & $=0.049$ & 25.277 & 0.001 \\
\hline 151 & $\therefore$ 且 & , & 80.096 & -0.069 & 25.715 & 0.001 \\
\hline ， 而 & 17 & i & $9-0.091$ & -0.033 & 26.128 & 0.002 \\
\hline 11 & : & i & $\begin{array}{ll}10 & 0.051\end{array}$ & -0.247 & 26.265 & 0.003 \\
\hline 11 & 7 & $i$ & 110.075 & 0.035 & 26.571 & 0.005 \\
\hline [ & 11 & 1 & $12-0.126$ & -0.020 & 27.466 & 0.007 \\
\hline & 10 & 1 & $\begin{array}{ll}13 & 0.057\end{array}$ & .0 .118 & 27.659 & 0.010 \\
\hline 1 远 & 目 & i & $14-0.098$ & -0.144 & 28.256 & 0.013 \\
\hline 171 & .7 & , & $15-0.044$ & -0.012 & 28.380 & 0.019 \\
\hline 1 11 & $a b$ & I & $\begin{array}{ll}16 & 0.063\end{array}$ & 0.050 & 28.652 & 0.026 \\
\hline
\end{tabular}

Figure 3. Correlogram for BT at first difference
The above correlogram shows that the autocorrelation function has spike at lag one and five and the partial correlation function has spike at lag one and three. These patterns suggest ARIMA models such as $\operatorname{ARIMA}(1,1,0)$, $\operatorname{ARIMA}(3,1,0), \quad \operatorname{ARIMA}(0,1,1), \quad \operatorname{ARIMA}(0,1,5)$, $\operatorname{ARIMA}(1,1,1), \quad \operatorname{ARIMA}(1,1,5), \quad \operatorname{ARIMA}(3,1,1) \quad$ and $\operatorname{ARIMA}(3,1,5)$.

\subsection{Model Diagnostic}

The third step will be the formal assessment of each of the time series models. This involves a rigorous assessment of diagnostic tests for each of the competing models. As different models may perform reasonably similar, a number of alternative formulations may have to be retained at this stage with further assessment to be done at the forecasting stage. There are a number of diagnostic tools available for ensuring a satisfactory model is arrived at. Plotting the residuals of the estimated models is a useful diagnostic check. This should indicate any outliers that may affect parameter estimates and also point towards any possible autocorrelation problem. If a model is correctly specified, the residuals should be white noise. Therefore, the plot of autocorrelogram should immediately die out from one lag on. That is, if the residuals are truly random, the autocorrelations and partial autocorrelations calculated using the residuals should be statistically equal to zero at all lags. If they are not, this is an indication that the fitted model is not good.

\subsubsection{Assessing the Fitted Model}

The following table shows that the selected ARIMA model with corresponding penalty function statistics.

Table 4. Model summery for selected ARIMA models

\begin{tabular}{|c|c|c|c|c|c|c|}
\hline \multirow{2}{*}{ Selectedmodels } & \multicolumn{6}{|c|}{ Penalty function statistics } \\
\hline & R2 & $\operatorname{Adj} R^{2}$ & SSE & AIC & SC & SerialCorrelation \\
\hline $\operatorname{ARIMA}(1,1,0)$ & 0.2184 & 0.1902 & 2185.03 & 18.27 & 18.36 & Yes \\
\hline $\operatorname{ARIMA}(3,1,0)$ & 0.5068 & 0.4539 & 1842.25 & 18.18 & 18.18 & No \\
\hline $\operatorname{ARIMA}(0,1,1)$ & 0.1382 & 0.1121 & 2261.43 & 18.43 & 18.43 & Yes \\
\hline $\operatorname{ARIMA}(0,1,5)$ & 0.4968 & 0.4099 & 1843.48 & 18.29 & 18.29 & No \\
\hline $\operatorname{ARIMA}(1,1,1)$ & 0.2165 & 0.166 & 2217.48 & 18.46 & 18.46 & Yes \\
\hline $\operatorname{ARIMA}(1,1,5)$ & 0.4934 & 0.3819 & 1909.01 & 18.44 & 18.44 & No \\
\hline $\operatorname{ARIMA}(3,1,5)$ & 0.6653 & 0.5489 & 1674.38 & 18.05 & 18.05 & Yes \\
\hline
\end{tabular}

As we know the model with small AIC and BIC is preferable. Based on these selection criteria, ARIMA $(3,1,5)$ seems the best. However, the residual were found to be serially correlated. Based on the value of $\mathrm{R}^{2}$ and adjusted
$\mathrm{R}^{2}$ (in addition to AIC and SC), the model ARIMA $(3,1,0)$ is selected for further assessment. The results are shown below.

\subsection{Candidate Model}

Table 5. Estimated model for ARIMA $(3,1,0)$.

\begin{tabular}{|c|c|c|c|c|}
\hline Variable & Coefficient & Std. Error & t-Statistic & Prob. \\
\hline$\emptyset_{0}$ & -1221.923 & 768.5460 & -1.559915 & 0.1231 \\
\hline$\emptyset_{1}$ & -0.554338 & 0.165740 & -3.344625 & 0.0024 \\
\hline$\emptyset_{2}$ & 0.359399 & 0.184834 & 1.944437 & 0.0620 \\
\hline$\emptyset_{3}$ & 0.704504 & 0.179617 & 3.922256 & 0.0005 \\
\hline R-square & 0.506761 & \multicolumn{2}{|c|}{ Mean dependent var } & -894.0527 \\
\hline Adjusted R-square & 0.453914 & \multicolumn{2}{|c|}{ S.D. dependent var } & 2492.977 \\
\hline S.E. of regression & 1842.251 & \multicolumn{2}{|c|}{ Akaike info criterion } & 17.99183 \\
\hline
\end{tabular}




\begin{tabular}{|c|c|c|c|c|}
\hline Variable & Coefficient & Std. Error & t-Statistic & Prob. \\
\hline Log likelihood & -283.8693 & Hannan-Quinn criter. & & 18.05256 \\
\hline $\begin{array}{l}\text { F statistic } \\
\text { Prob. (F statistic ) }\end{array}$ & $\begin{array}{l}9.589207 \\
0.000161\end{array}$ & Durbin-Watson stat & & 1.842203 \\
\hline
\end{tabular}

The candidate model is ARIMA $(3,1,0)$ model. The estimated ARIMA $(3,1,0)$ model together with the diagnostic test results are shown in table 5 below.

We can write the ARIMA $(3,1,0)$ model as follows:

$$
\nabla Y_{t}=-1221.9-0.6 \nabla Y_{t-1}+0.4 \nabla Y_{t-2}+0.7 \nabla Y_{t-3}+\varepsilon_{t}
$$

After some mathematical manipulations the estimated model becomes:

$$
\begin{gathered}
\nabla Y_{t}=-1221.9+0.4 \nabla Y_{t-1}+0.9 \nabla Y_{t-2}+0.3 \nabla Y_{t-3} \\
-0.3 \nabla Y_{t-4}+\varepsilon_{t}
\end{gathered}
$$

The Jarque-Bera statistic and Q-statistics of the correlogram of residuals squared are not significance. These values indicate that, the candidate model full fills the assumption of normality and no heteroskedasticity in the residual.

\subsection{Evaluation of In-Sample Forecast}

The forecasting performance of a model can be examined by the standardized statistical tools such as root mean square error, mean absolute error, mean absolute percentage error and Theil's inequality. But as discussed in the methodology part, mean absolute percentage error and Theil's inequality are unit-less and preferable. Due to this, we consider the values of mean absolute percentage error (MAPE) and Theil's inequality (TI).

Table 6. Summary table for ARIMA(3,1,0) model

\begin{tabular}{ll}
\hline Statistical tools & ARIMA(3,1,0) \\
\hline RMSE & 1723.268 \\
MAE & 1304.767 \\
MAPE & 29.91570 \\
TIC & 0.077181 \\
Bias proportion & 0.000000 \\
Variance proportion & 0.062371 \\
Covariance proportion & 0.937629 \\
\hline
\end{tabular}

The mean absolute percentage error and Theil's inequality for ARIMA $(3,1,0)$ model were 29.91570 and 0.077181, respectively. The value of Theil's inequality is close to one. This value indicates that the forecasting performance of the model is good. The other model fit criteria also point towards the ARIMA $(3,1,1)$ model has good forecasting performance (meaning that Figure 4 shows that the line of actual and forecasted is overlap each other). Thus, we consider this model for out-of-sample forecast. A graph of the actual and the ARIMA $(3,1,0)$ in-sample fit values of trade balance is shown in Figure. 4 below.

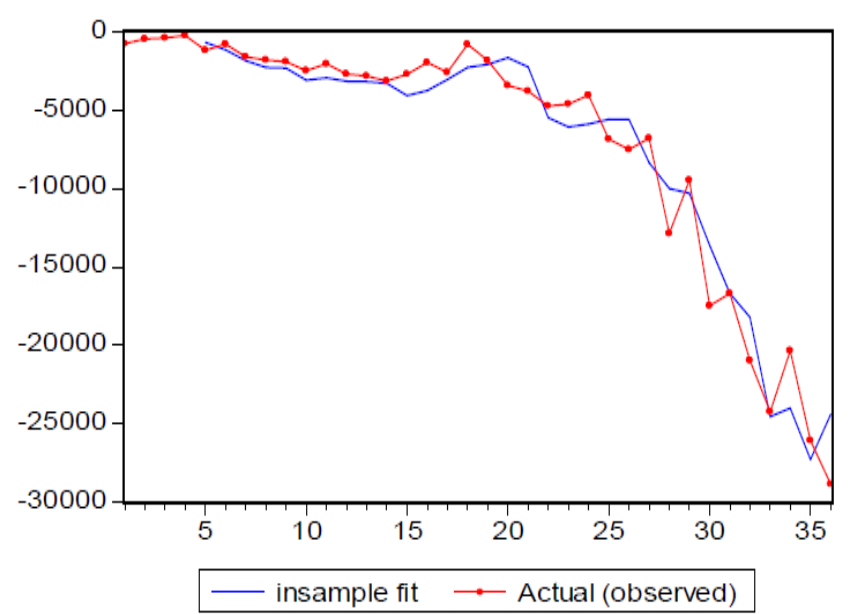

Figure 4. Actual versus forecasted graph for balance of trade

\subsection{Forecasting}

We have the estimated ARIMA $(3,1,0)$ model from the estimation part. Then we can forecast the value of balance of trade in Ethiopia based on the fitted model from year 2011/12 up to $2015 / 16$. The forecasted results are given in the Table 7 and it indicates that the deficit in balance of trade is expected to keep on rising.

Table 7. Forecasted value of ARMA model from 2010/11 to 2015/16

\begin{tabular}{ll}
\hline Year & Forecasted real BT(in billion birr) \\
\hline $2010 / 11$ & -35.40 \\
$2012 / 13$ & -37.83 \\
$2013 / 14$ & -39.06 \\
$2014 / 15$ & -40.27 \\
$2015 / 16$ & -41.50 \\
\hline
\end{tabular}

\section{Conclusion}

The objective of this study was to model and forecast the balance of trade in Ethiopia by using ARIMA model. The balance of trade was modeled as $\operatorname{ARIMA}(3,1,0)$ and I has shown some improvements in the years 2002/03 and 2006/07. However, these improvements were short lived (temporary) in the sense that the balance of trade keeps on increasing negatively in subsequent years. Based on this fitted ARIMA $(3,1,0)$ model the balance of trade is forecasted from the year $2011 / 12$ up to $2015 / 16$. The forecasted result shows that the deficit in the balance of trade in Ethiopia is expected to increase from 2011/12 up to 2015/16.

\section{Recommendation}

As we have seen in the ARIMA forecasted result the value of balance of trade is mounted negatively in all forecasted year. This result indicates that there exist unbalance between value 
of import and export in the country. The government should consider different types of solutions and implement different type of policies to overcome this problem in the country.

\section{List of Abbreviations}

ADF: Augmented dickey fuller

ARIMA: Auto regressive integrated moving average

BT: Balance of trade

MoFED: Ministry of Finance \& Economic Development

NBE: National Bank of Ethiopia

USD:United State Dollar

\section{References}

[1] Box, G.E.P. and G.M. Jenkins (1970). Times Series Analysis: Forecasting and Control. Holden-Day, San Francisco, CA.

[2] Challen, J. and Hagger, S. (1983). Economics; Mathematical models. St. Martin's Press, New York.
[3] Dickey, D. A. and W. A. Fuller (1979). Distribution of the Estimators for Autoregressive Time Series with a Unit Root. Journal of the American Statistical Association, Vol. 74, PP. 427-431.

[4] Enders, W. (1995). Applied Econometric Time Series. Giles and Mizra, New York.

[5] Greene, W.H (2003). Econometric Analysis, 5th edition. Pearson Education, Inc., Upper Saddle River, New Jersey.

[6] Maddala, G.S (1992). Introduction to Econometrics, 2nd edition. University of Florida and Ohio state university, Macmillan, New York.

[7] National Bank of Ethiopia (2007/08). Annual Report. Documentation and Publication Service, Addis Ababa.

[8] Negadras Gebrehiwot Baykedagn (1912). Emperor Minlik and Ethiopia. Ethiopia, Addis Ababa.

[9] Nelson, C. and Plosser, C. (1982). Trends and Random Walks in Macroeconomic Time Series: Some Evidence and Implications. Journal of Monetary Economics, Vol. 10, PP. 130-162. 